\title{
Defending science against anti-science
}

\author{
There is a need for concerted action against the forces of anti-science; simply ignoring the critics will \\ not suffice to counter the phenomenon.
}

JoHN Ziman's recent review of Gerald Holton's latest book (Nature 367, 522; 1994) will have prompted many people to read not just the review, with its stirring warnings of the dangers of "anti-science" (part of Holton's title), but the book itself. That is what publishers and authors hope that reviewers will do for them. Ziman has done the job excellently.

But many who follow Ziman's signpost may be disappointed. Holton's essay on "The anti-science phenomenon" is the last in a collection that begins with an essay on Ernst Mach's influence on science in the early decades of this century. Legend (and Einstein's slightly ambiguous expression of gratitude) has it that Mach's positivism helped in constructing the foundation of relativity. It remains in dispute whether Mach repudiated his delight in what his disciple had wrought. The truth is that Mach stimulated "the unity of science" movement that sporadically occupied European and American science in the 1920s and 1930s. In that sense, Mach is a good foil for anti-science.

The disappointment is not so much with substance as with style. Holton's defence of science against its detractors is, inevitably in the circumstances, cool, even quasi-philosophical. It is all there, but too measured for many tastes, and the present need.

Take, for example, astrology. It is a plain fact that astrology is a pack of lies in the literal sense; those who peddle horoscopes do so on an explicit set of statements about the real world that cannot be correct. There is no evidence that the positions of the planets can affect human behaviour, nor any plausible mechanism by which they could do so. It would not matter if the lies were told in some other context, say the alleged link between stock-exchange prices and the popularity of rock-and-roll music. That they are told, and believed by countless innocents, in flat contradiction of the more objective view of the world accumulated over centuries, means that each and every horoscope is, by denying the objective view of the planets, an attack on the probity of science.

Holton makes that point, and also notes that the scientific profession is docile in the face of what is really a torrent of attack. But is it not disgraceful that there should be such general and benign tolerance of astrology (and other mumbo-jumbo such as faith healing, water divining and spiritualism), apparently on the grounds that they are the harmless pursuits of people who are not scientists? Would other professionals, lawyers or accountants say, be as tolerant of NATURE · VOL 368 - 17 MARCH 1994 public belief that undermined the integrity of their work - and, potentially, their livelihood?

Religion is something else again. As the long (and soon to end) correspondence in Nature has shown, many professional scientists are deeply religious, often justifying their belief on the grounds that "science cannot know everything". That science does not know everything is, of course, accepted generally. Professional people might even more openly acknowledge that much of what is known may be incorrectly (or incompletely) known. The idea that religion may be a way of organizing one's appraisal of one's place in the world is not very different from what astrologers tell their clients. In other words, it may not be long before the practice of religion must be regarded as anti-science. Holton, who skirts round this issue, is nevertheless correct in saying that 'creation science', as its practitioners call it, deserves the fiercest counterattack, especially now that so many of its practitioners have qualified as scientists and engineers, and so are all the more insidious because they know the language.

In reality, of course, there are many more contemporary attacks on science than astrology and religion. Moreover, they are more direct, and often sustained by people even better qualified in science or engineering than those recruited by the creationists. Yet that has not prevented the engagement of these well advised pressure groups in public issues by exploiting the willingness of the general public to be frightened by issues they do not understand. Similar problems arise with nuclear power and genetics; the pressure groups draw attention to many problems that need to be resolved, but then frighten the rest of the world into believing that problems not yet tackled spell potential catastrophe for some section of the community or the whole of it.

Because those who formulate these exaggerated arguments are often themselves members of the scientific community by qualification, they deserve respect, and not the disdain they usually enjoy. That is an error that creates more trouble than it saves. The usual reaction to those who perpetrate inferior contributions in the scientific literature, that their publications do not command serious attention, does not (or should not) apply to false statements of the view of the world equated with science. They deserve, but do not get, the treatment appropriate for astrology.

There is an obvious danger in a policy by which the scientific community defends itself against anti-science exclusively by saying that its critics are mistaken. That would seem mean-minded to say the least of it. That is why Holton's references to Mach, and to Mach's earnest contemporaries, is an especially apt lesson for the present. Then, there was a 'world view' of science from which Mach's advocacy of the unity of science sprang. Now there are a half a dozen conflicting views (which Holton lists) which make it difficult for science to present a coherent counter to anti-science.

There are several distractions, of which the long argument about the death of physics is the most irrelevant. The issue goes back to the closing decades of the nineteenth century, when the practitioners of newtonian mechanics held that the problems they could not understand represented a failure of physics, but in the modern world is represented by those who argue that it needs only one last push to unify the four fundamental forces of nature, whereupon the whole of fundamental physics will be represented by a single formula. The optimism would be believable if anybody could explain how the missing step - the quantization of grayity - can be taken without changing our view of what the world is really like.

Yet Holton is right to insist that science needs a description of what it says (or will say) about the world that can lend coherence to its defence against its critics. For that matter, with this millennium coming to an end, it could be held that science needs such a description for its own belief in what it is about. These are the essential ingredients of what needs saying.

First, truth is not absolute, but rather a series of working hypotheses that are defined by increasingly rigorous rules; that means that the range of credible heterodoxy steadily diminishes. Second, to stifle arid arguments on questions such as the propriety of reductionism, it would suffice to say that science takes as its general working hypothesis the notion that all systems (in physics and biology) contain the ingredients and forces of their own evolution. That does not mean that the future is predictable from the present, for accidents (such as the $\mathrm{K} / \mathrm{T}$ impact) will always happen. And finally, the purpose of it all is to understand the world more fully for no other purpose than the enhancement of the general enlightenment. Holton has done a public service in drawing attention to the threat of anti-science. He needs a polemicist to take the fight against it.

John Maddox 